\title{
Transgenic expression of omega-3 PUFA synthesis genes improves zebrafish survival during Vibrio vulnificus infection
}

Chih-Lun Cheng ${ }^{1,2+}$, Shin-Jie Huang ${ }^{1,3+}{ }^{+}$Chih-Lu Wu ${ }^{1}$, Hong-Yi Gong ${ }^{4}$, Chuian-Fu Ken ${ }^{5}$, Shao-Yang Hu ${ }^{6}$ and Jen-Leih $\mathrm{Wu}^{1,2,3^{*}}$

\begin{abstract}
Background: Highly desaturated n-3 polyunsaturated fatty acids (PUFAs), such as eicosapentaenoic acid (EPA) and docosahexaenoic acid (DHA), are synthesized by desaturases and elongase. They exert hepatoprotective effects to prevent alcoholic fatty liver syndrome or cholestatic liver injury. However, it is unclear how n-3 PUFAs improve immune function in liver. Vibrio vulnificus, a gram-negative bacterial pathogen, causes high mortality of aquaculture fishes upon infection. Humans can become infected with $V$. vulnificus through open wounds or by eating raw seafood, and such infections may result in systemic septicemia. Moreover, patients with liver diseases are vulnerable to infection, and are more likely than healthy persons to present with liver inflammation following infection. This study quantified n-3 PUFAs and their anti-bacterial effects in Fadsd6 and Elvol5a transgenic zebrafish.
\end{abstract}

Results: Two transgenic zebrafish strains with strong liver specific expression of Fadsd6 and Elvol5a (driven by the zebrafish Fabp 10 promoter) were established using the Tol2 system. Synthesis of n-3 PUFAs in these strains were increased by 2.5 -fold as compared to wild type (Wt) fish. The survival rate in $24 \mathrm{~h}$ following challenge with $V$. vulnificus was $20 \%$ in Wt, but $70 \%$ in the transgenic strains. In addition, the bacteria counts in transgenic fish strains were significantly decreased. The expression levels of pro-inflammatory genes, such as TNF- $a, I L-1 \beta$, and NF-KB, were suppressed between 9 and $12 \mathrm{~h}$ after challenge. This study confirms the anti-bacterial function of $\mathrm{n}-3$ PUFAs in a transgenic zebrafish model.

Conclusions: Fadsd6 and Elvol5a transgenic zebrafish are more resistant to $V$. vulnificus infection, and enhance survival by diminishing the attendant inflammatory response.

Keywords: Omega-3 PUFAs, Anti-inflammation, Anti-bacteria, Vibrio vulnificus, Transgenesis

\section{Background}

Docosahexaenoic acid (DHA, 22: $6 \mathrm{n}$-3) and eicosapentaenoic acid (EPA, 20:5 n-3) are formed through desaturation and elongation of $\alpha$-linolenic acid (ALA, 18: $3 n-3$ ), as catalyzed by pivotal desaturases and elongase $[1,2]$. Omega- 3 polyunsaturated fatty acids (n-3 PUFAs), such as DHA and EPA, are abundant in marine organisms. Salmon, tuna, and mackerel can efficiently synthesize EPA and DHA after

\footnotetext{
* Correspondence: jlwu@gate.sinica.edu.tw

${ }^{\dagger}$ Equal contributors

${ }^{1}$ Institute of Cellular and Organismic Biology, Academia Sinica, Taipei 115, Taiwan

Institute of Bioscience and Biotechnology, National Taiwan Ocean University, Keelung 202, Taiwan

Full list of author information is available at the end of the article
}

feeding on marine algae and phytoplankton that contain large amounts of ALA. However, most vertebrates, including humans, cannot synthesize high levels of long chain $n$-3 PUFAs because the essential desaturases in these species are not sufficiently efficient [3]. Fish oils are thus important and abundant sources of long chain n-3 PUFAs for humans [2, 4, 5]. However, over-consumption and heavy metal contamination of marine fishes are critical problems for their use in the human diet [6-8]. Advances in aquaculture techniques and transgenesis have enabled the farming of fish that synthesize high levels of n-3 PUFAs, and thus farmed fish unexposed to metal pollution can substitute for marine fishes as sources of fish oils.

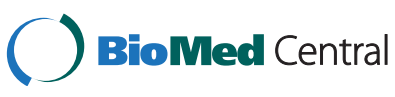

(c) 2015 Cheng et al. Open Access This article is distributed under the terms of the Creative Commons Attribution 4.0 International License (http://creativecommons.org/licenses/by/4.0/), which permits unrestricted use, distribution, and reproduction in any medium, provided you give appropriate credit to the original author(s) and the source, provide a link to the Creative Commons license, and indicate if changes were made. The Creative Commons Public Domain Dedication waiver (http://creativecommons.org/publicdomain/zero/1.0/) applies to the data made available in this article, unless otherwise stated. 
Various n-3 PUFAs have been reported to exert beneficial effects, such as protection against liver diseases, regulation of cholesterol, and reduction of blood pressure, which prevents cardiovascular diseases (CVDs) [9, 10]. On the other hand, some studies have indicated that n-3 PUFAs exert anti-inflammatory effects by regulating the expression of peroxisome proliferator activated receptors (PPARs) and nuclear factor kappa B (NF-kB) [11-13]. The inflammatory response is triggered by activation of NF- $\mathrm{kB}$, which induces the expression of pro-inflammatory cytokines, adhesion molecules, chemokines, growth factors, and inducible enzymes, such as cyclooxygenase 2 (COX-2) and nitric oxide synthase (NOS) [14]. In an earlier study, COX was shown to be able to convert arachidonic acid (AA, 20:4 n-6) into prostaglandin (PG)- $\mathrm{H}_{2}$ to enhance inflammation. In contrast, the other substrate for COX is EPA, which is not only an inhibitor of AA metabolism, but also an alternative substrate for COX-mediated synthesis of $\mathrm{PGH}_{3}$, an anti-inflammatory cytokine. Furthermore, other inflammatory mediators, such as tumor necrosis factor- $\alpha$ (TNF- $\alpha$ ) and interleukin-1 $\beta$ (IL-1 $\beta)$, are inhibited by EPA [8]. Hence, n-3 PUFAs improve many chronic syndromes by suppressing inflammation [9].

EPA and DHA also exhibit significant anti-bacterial effects against Propionibacterium acnes and Staphylococcus aureus [15]. In 2005, Li et al. demonstrated that both EPA and DHA down-regulate lipopolysaccharide (LPS) -induction inflammation in human kidney-2 (HK2) cells [16]. These findings indicate that n-3 PUFAs are efficient at preventing inflammation induced by bacterial infection.

Vibrio vulnificus (V. vulnificus) is a gram-negative bacterium which causes infectious disease and striking mortality, mostly due to septicemia [17]. Infection in humans is caused by wound exposure or consumption of raw sea food. Rapid progression to septicemia following $V$. vulnificus infection is associated with high mortality [18]. Moreover, patients with liver diseases are particularly vulnerable to infection, and are more likely than healthy persons to present with inflammation upon infection [19]. On the other hand, vibriosis has resulted in serious economic losses in aquaculture in Japan and Europe [20]. $V$. vulnificus induces the host immune response through TLRs and their downstream genes, NF- $\mathrm{B}$, which translocates to the nucleus and leads to inflammation [21, 22].

Most fresh water fish lack the n-3 PUFAs and can't protect from bacterial infection. We try to increase the n-3 PUFAs by transgenic fish. Because the liver is the major organ for lipid metabolism, it is also a target of $V$. vulnificus [23]. According to the n-3 PUFAs biosynthesis pathway, fatty acid desaturase- $\Delta 6$ (Fadsd6) is the rate limited step and elongase (Elvol5a) is also important $[3,24]$. In this study, we demonstrated that liver-specific overexpression of Fadsd6 and Elvol5a in transgenic zebrafish exerts protection from $V$. vulnificus infection. Our findings suggest that liver-specific expression of Fadsd6 or Elvol5a enhances the bio-synthesis of EPA and DHA in transgenic zebrafish, and this is sufficient to increase the survival rate in response to $V$. vulnificus challenge.

\section{Methods}

\section{Zebrafish maintenance}

Wild-type (AB) zebrafish (Danio rerio) was maintained under standard conditions (water-flow tanks at $28.5{ }^{\circ} \mathrm{C}$ with a $12 \mathrm{~h}$ light/12 $\mathrm{h}$ dark cycle). Zebrafish was fed on a commercial diet twice a day. The embryos were collected through natural matching and cultured in a $28.5{ }^{\circ} \mathrm{C}$ incubator. All conditions for maintaining zebrafish were as previously described (Westerfield, M., 2007) [25].

Research was conducted in compliance with the principles stated in the Guide for the Care and Use of Laboratory Animals, National Research Council, 1996. All animal experiments in this study were approved by the Academia Sinica Institutional Animal Care \& Utilization Committee (AS IACUC).

\section{Construction of transgenic fish}

Plasmids contained the Fabp10 promoter, which was used to drive a tetracycline-controlled transactivator (tTA) and either the TcFP13 (GFP) or TcFP11 (RFP) reporter genes. The Fadsd6 and Elvol5a genes of Atlantic salmon (Salmo salar) were individually flanked by the Tol 2 transposon element, and placed downstream of the tetracycline responsive element. This liver-specific gene expression system was modified from that described in our previous publication [26].

Transposase messenger RNA (mRNA) was co-injected with vectors into embryos (at the one-cell stage), and excision efficiency assays were performed as described [27]. Injected fish were cultured to sexual maturity and outcrossed to identify germ line transgenic fish.

\section{Zebrafish RNA extraction and quantitative RT-PCR}

RNA from zebrafish liver tissue was extracted with TRIzol reagent (Invitrogen) and reverse transcribed to cDNA using the High Capacity cDNA Reverse Transcription Kit (Applied Biosystems). Quantitative real time-PCR was performed using a LightCycler480 system (Monocolor hydrolysis UPL-probe, Roche Applied Science). The Q-PCR synthesis mix reagents included $5 \mu \mathrm{L}$ Master Buffer (Roche Applied Science), $2 \mu \mathrm{L}$ each primer $(2 \mu \mathrm{M}), 0.1 \mu \mathrm{L}$ probe (the numbers in Table 1 correspond to each primer pair), $2.5 \mu \mathrm{L}$ cDNA ( $80 \mathrm{mg} / \mathrm{mL}$, diluted 100 times), and $0.4 \mu \mathrm{L}$ ultra-pure water. The sequences of the primers used are listed in Table 1. For analysis of gene expression, we determined the relative expression value $\left(2_{\mathrm{T}}^{-\Delta \Delta \mathrm{C}}\right)$ for each gene by subtracting the $\Delta \mathrm{C}_{\mathrm{T}}$ value of the 
Table 1 Primer list of RT-PCR and quantitative RT-PCR

\begin{tabular}{|c|c|c|c|}
\hline Primer & Gene name & Sequence & Universal probe NO. \\
\hline \multirow[t]{2}{*}{$\mathrm{EF}-1 \mathrm{a}$} & Elongation factor-1alpha & F: cctctttctgttacctggcaaa & $\# 73$ \\
\hline & & R: cttttcctttcccatgattga & \\
\hline \multirow[t]{2}{*}{ TNF-a } & Tumor necrosis factor-alpha & F: aggcaatttcacttccaagg & \# 158 \\
\hline & & R: aggtctttgattcagagttgtatcc & \\
\hline \multirow[t]{2}{*}{$\operatorname{cOX}-2 \mathrm{a}$} & Cyclooxygennase-2a & F: agccctactcatcctttgagg & \# 161 \\
\hline & & R: tcaaccttgtctacgtgaccata & \\
\hline \multirow[t]{2}{*}{$I L-1 \beta$} & Interleukin-1 beta & F: acgtctccacatctcgtactca & \# 12 \\
\hline & & R: tcgaaggtgtttatggagctg & \\
\hline \multirow[t]{2}{*}{$\| \mathrm{L}-15$} & Interleukin-15 & F: aggctcaggagaagactcacc & $\# 9$ \\
\hline & & R: ggatgtcgtgctgagcaat & \\
\hline \multirow[t]{2}{*}{ Lysozyme } & Lysozyme & F: gggattctccattggcaac & $\# 48$ \\
\hline & & R: ctcggtgggtcttaaacctg & \\
\hline \multirow[t]{2}{*}{ NF-KB 1} & Nuclear factor kappa B1 & F: gcatctgcatctccgaca & \# 109 \\
\hline & & R: tgcccaaattagggaaactg & \\
\hline \multirow[t]{2}{*}{ Fadsd2 } & Fatty acid desaturase 2 & F: tcaggaccggcagaaaaa & $\# 41$ \\
\hline & & R: aacagcggctgcgtttta & \\
\hline \multirow[t]{2}{*}{ Elovl2 } & Elongase 2 & F: tggacagcctatttggagaaa & \#66 \\
\hline & & R: gcaaaaatgttggtgtgtagga & \\
\hline \multirow[t]{2}{*}{ Elovl5 } & Elongase 5 & F: ccaaatctcttacatggtcacg & \#15 \\
\hline & & R: tcccgaacgtttcttataggtc & \\
\hline \multirow[t]{2}{*}{ RT-Fadsd6 (V5-tag) } & Fatty acid desaturase delta6 & F: atggggggcggaggccagcag & - \\
\hline & & R: gaatcgagaccgaggagaggg & \\
\hline \multirow[t]{2}{*}{ RT-Elvol5a (V5-tag) } & Elongase & F: atggagacttttaattataaac & - \\
\hline & & R: gaatcgagaccgaggagaggg & \\
\hline \multirow[t]{2}{*}{ RT- $\beta$-actin } & Beta-actin & F: cacggcatcattaccaactg & - \\
\hline & & R: gtacggccagaagcgtagag & \\
\hline
\end{tabular}

control sample from that of the infected sample (i.e. $\left.\Delta \Delta \mathrm{C}_{\mathrm{T}}\right)$. Values are presented as relative fold expression levels with the standard error; results from at least three independent experiments were averaged.

\section{Western blots and antibodies}

To examine expression of proteins in transgenic fish, total proteins were extracted from zebrafish tissue (approximately $50 \mathrm{mg}$ ) and added to $500 \mu \mathrm{L} 2$-D rehydration sample buffer with $5 \mu \mathrm{L}$ ready prep TBP reducing agent (Ready-Prep Protein Extraction Kit, Bio-Rad). After centrifugation at top speed for $20 \mathrm{~min}$ at $18{ }^{\circ} \mathrm{C}, 300 \mu \mathrm{L}$ supernatants were collected and transferred to new $1.5 \mathrm{~mL}$ microcentrifuge tubes, and kept at $-80{ }^{\circ} \mathrm{C}$ for long-term storage. Protein concentrations were determined using a Protein Assay Kit (595 nm, Bio-Rad). For Western blot, protein samples (100 mg) were separated using the NuPAGE Bis-Tris Mini Gel Kit (Invitrogen) and transferred to a $0.45 \mathrm{~nm}$ PVDF membrane (Millipore, Bedford) using a trans-blot SD cell (Bio-Rad). Membranes were blocked with $5 \%$ milk (Anker) for $1 \mathrm{~h}$, and then rinsed three times with PBS (Bioman) for 5 min with shaking; next, membranes were incubated with primary Anti-V5 antibody (1:1000 dilution; Invitrogen) overnight at $4{ }^{\circ} \mathrm{C}$. Samples were incubated with $\beta$-actin antibody (1:5000 dilution; Invitrogen) as an internal control; after washing to remove excess antibody, samples were incubated with secondary antibody (anti-mouse; Millipore) for $1 \mathrm{~h}$ at room temperature with shaking, and then washed as described above. Membranes were exposed to Immobile Western Chemiluminescent HRP Substrate (Millipore), and proteins were then detected using an Imaging System (UVP).

\section{Fatty acid extraction and analysis}

For fatty acid analysis of transgenic lines and wild-type zebrafish, total lipids were extracted with organic solvent (chloroform: methanol 2:1, containing BHA $0.05 \mathrm{mg}$, Sigma), using a previously described method (Folch et al. 1957) [28]. Crude lipids were saponified through incubation for $20 \mathrm{~min}\left(\right.$ reflux at $90{ }^{\circ} \mathrm{C}$ ) with $1 \mathrm{~mL}$ of $\mathrm{KOH}(50 \%$, 
Merck), $15 \mathrm{~mL}$ of alcohol (90\%, Merck), and boiling stones. After being allowed to cool, the hydrophilic samples were purified and washed with $30 \mathrm{~mL}$ water and then $40 \mathrm{~mL}$ ethyl ether (this wash step was repeated three times). Pure fatty acids in the organic layer were reduced through the addition of $50 \mathrm{~mL}$ of ethyl ether, 2-3 drops of methyl orange, and $10 \mathrm{~mL}$ of $2 \mathrm{~N} \mathrm{HCl}$ (Merck); the organic layer was then shaken lightly for $1 \mathrm{~min}$. The organic layer (approximately $50 \mathrm{~mL}$ ), which contains hydrophobic samples, was washed with water $(50 \mathrm{~mL})$ 4-5 times until the $\mathrm{pH}$ value became neutral; the layer was then evaporated with a vacuo concentrator (Eyela). During the methyl esterification steps, the sample (approximately $100 \mathrm{mg}$ ) was incubated with $5 \mathrm{~mL}$ of $\mathrm{BF}_{3}-\mathrm{MeOH} 7 \%$ (Boron trifluoride-methanol solution, $14 \%$, Sigma) and boiling stones for $40 \mathrm{~min}$ (reflux at $90{ }^{\circ} \mathrm{C}$ ). Subsequently, $5 \mathrm{~mL}$ hexane (Sigma) was added, and the sample was incubated for an additional $1 \mathrm{~min}$. Fatty acid methyl esters (approximately $5 \mathrm{~mL}$ ) were dried and diluted with highly pure hexane $(100 \mathrm{mg} / \mathrm{mL})$. The samples were analyzed using an Agilent 5975C Series GC-MSD (Agilent). The Agilent column was $30 \mathrm{~mm} \mathrm{X} 0.25 \mathrm{~mm}$, with a film thickness of $0.25 \mathrm{~mm}$ (Crawford Scientific, Strathaven); conditions were as previously described (Abu, 2009) [29].

\section{Bacterial culture and challenge}

V. vulnificus was cultured on BHI (Brain heart infusion powder, BD Difco $\left.{ }^{\mathrm{min}}\right)$ agar plates containing $1.5 \% \mathrm{w} / \mathrm{v}$ sodium chloride (Merck) in a $30{ }^{\circ} \mathrm{C}$ incubator for $16 \mathrm{~h}$. A single colony of $V$. vulnificus was subsequently incubated in $300 \mathrm{~mL}$ BHI $(\mathrm{NaCl} 1.5 \%)$ media in a $30{ }^{\circ} \mathrm{C}$ incubator on a shaker operating at $200 \mathrm{rpm}$ for a further $16 \mathrm{~h}$. Subsequently, $30 \mu \mathrm{l}$ of bacteria were cultured with $300 \mu \mathrm{L}$ of $\mathrm{BHI}(\mathrm{NaCl} 1.5 \% \mathrm{w} / \mathrm{v})$ media in a $30{ }^{\circ} \mathrm{C}$ incubator on a shaker operating at $200 \mathrm{rpm}$ to obtain the appropriate concentration $\left(10^{7} \mathrm{CFU} / \mathrm{mL}\right)$.

Wild-type and transgenic zebrafish were challenged by intraperitoneal injection of $10 \mu \mathrm{L}$. vulnificus $\left(10^{4} \mathrm{CFU} /\right.$ $\mathrm{mL}$, diluted with PBS). Five fish were sacrificed at $0,1,3,6$, $9,12,24$, and $48 \mathrm{~h}$ after challenge for each group.

Liver samples were homogenized in $\mathrm{BHI}(\mathrm{NaCl} 1.5 \%$, $1 \mathrm{mg} / 20 \mu \mathrm{L}$ ) media, and the supernatants were serially diluted in $\mathrm{BHI}(\mathrm{NaCl} 1.5 \%, 1 \mathrm{mg} / 20 \mu \mathrm{L})$ media. Ten microliters of each dilution were spotted onto a TCBS (Thiosulfate-citrate-bile salts-sucrose, powder, BD Difco ${ }^{\mathrm{mm}}$ ) plate. Plates were incubated in a $30{ }^{\circ} \mathrm{C}$ incubator for $16 \mathrm{~h}$, and $V$. vulnificus colonies were then counted.

\section{Histological studies and TUNEL assay}

Liver tissue was fixed with $10 \%$ neutral formalin (Sigma) and embedded in paraffin. Sections with a thickness of $5 \mathrm{~mm}$ were prepared, and then stained with hematoxylin and eosin (H\&E, Thermo) for histological examination. DNA damage resulting from challenge with $V$. vulnificus was detected by subjecting paraffin-embedded sections to the TUNEL assay, using the In Situ Cell Death Detection kit, POD (Roche Applied Science).

\section{Statistical analysis}

The expression values of all the data are presented as the average \pm standard deviation (SD). Statistical analysis was performed using Student's $t$-test, and significance was set at ${ }^{*} \mathrm{P}<0.05,{ }^{* * *} \mathrm{P}<0.01$.

\section{Results}

Fadsd6 and Elvol5a are expressed in transgenic zebrafish liver

Two transgenic zebrafish lines with strong liver-specific expression of Fadsd6 and Elvol5a were generated. Each plasmid contained the Fabp10 promoter, which was used to drive a tetracycline-controlled transactivator (tTA) and either the TcFP13 (GFP) or TcFP11 (RFP) reporter genes. The Fadsd6 and Elvol5a genes of Atlantic salmon (Salmo salar) were flanked by the Tol2 transposon element, and placed downstream of the tetracycline responsive element (Fig. 1 (a)).

Either green or red fluorescence was observed in the liver of stably transgenic larvae expressing Fadsd6 or Elvol5a, respectively (Fig. 1 (b)). Ectopic gene expression of Fadsd6 or Elvol5a was detected in transgenic fish liver by the amplification of RT-PCR (Fig. 1 (c)). Western blots were performed to detect V5-tagged Fadsd6 or Elvol5a protein in liver tissue of transgenic fish, with $\beta$-actin as an internal control (Fig. 1 (d)). In summary, the transgenic zebrafish lines specifically overe-xpressed Fadsd6 and Elvol5a in liver.

\section{Synthesis of $n-3$ PUFAs was 2.5 - fold greater in Fadsd6 and Elvol5a transgenic zebrafish than in Wt}

Total lipid content was not significantly different between transgenic fish and Wt fish (Additional file 1: Table S1). EPA content was approximately 2.0 -fold higher in both Fadsd6 and Elvol5a transgenic fish than in Wt (Fig. 2 (a), Additional file 1: Table S1), while DPA content was 9.4-fold and 12.1-fold higher in Fadsd6 and Elvol5a transgenic fish than in Wt, respectively (Fig. 2 (b), Additional file 1: Table S1). DHA content was 2.9fold and 2.5-fold higher in Fadsd6 and Elvol5a transgenic fish than in Wt, respectively (Fig. 2 (c), Additional file 1: Table S1). As expected, total n-3 PUFAs content was 2.5-fold higher in Fadsd6 and Elvol5a transgenic fish than in Wt, respectively (Fig. 2 (d), Additional file 1: Table S1). No significant difference was observed between Wt fish fed on a commercial diet or artemia (Additional file 1: Table S1). These results indicate that $\mathrm{n}-3$ PUFAs synthesis is enhanced in transgenic fish over-expressing either Fadsd6 or Elvol5a. 
a

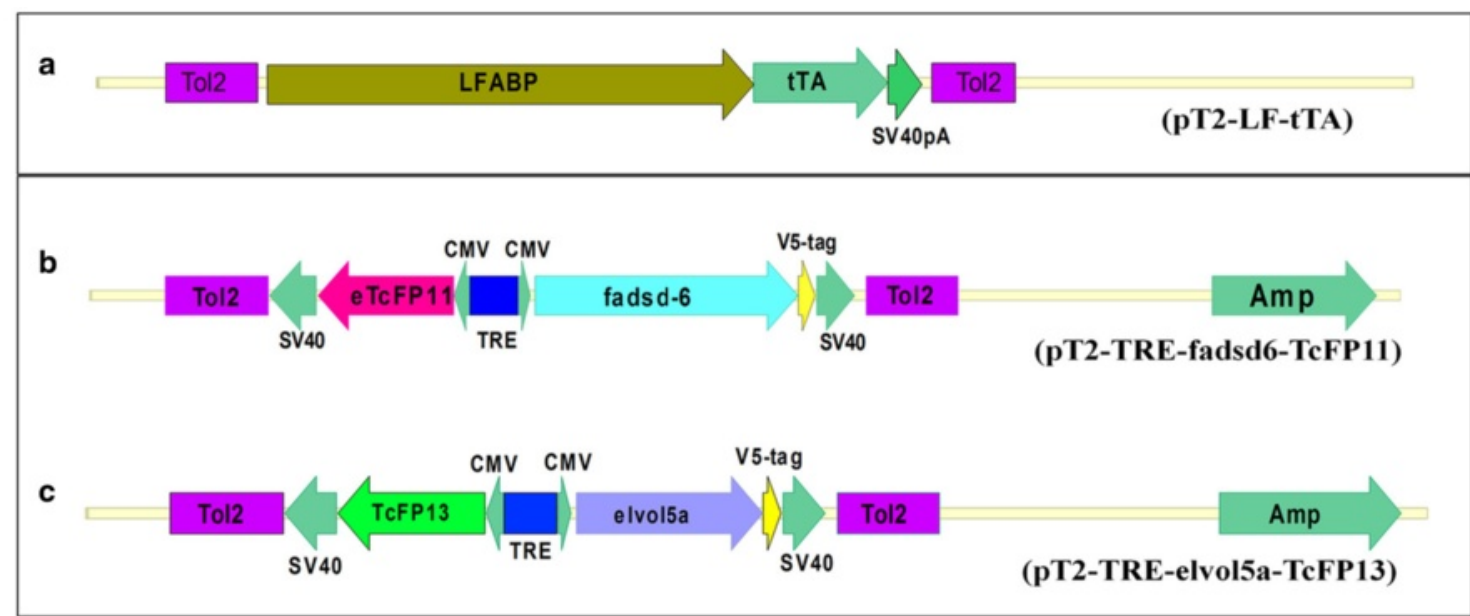

b

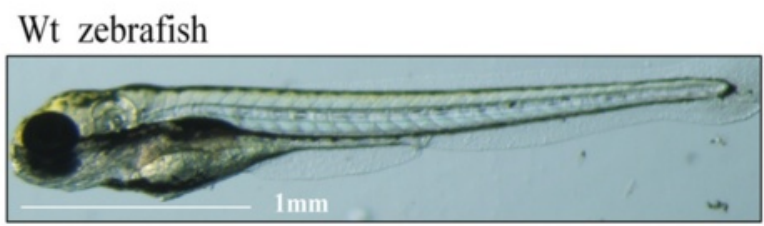

Tg: Fadsd6

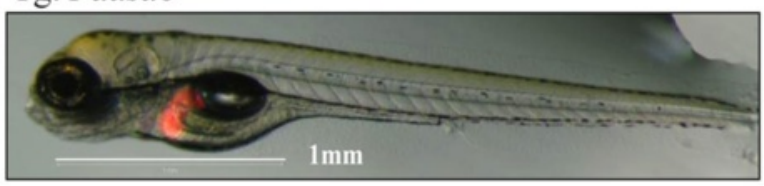

Tg: Elvol5a

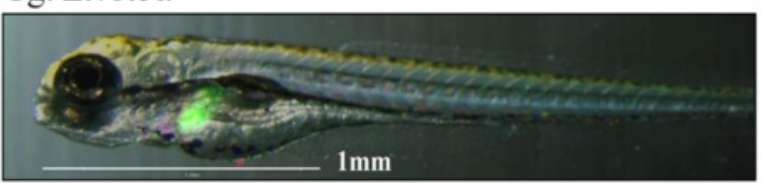

d
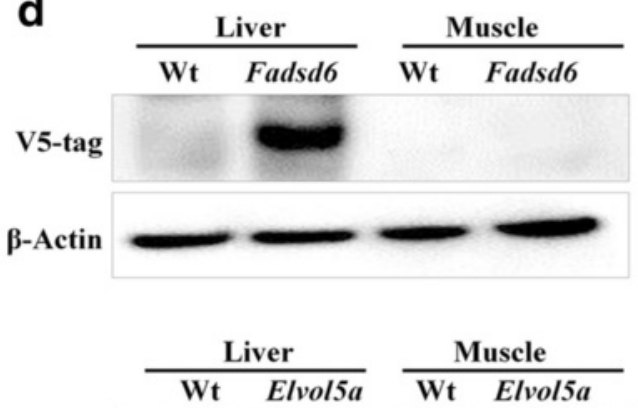

V5-tag

$\beta$-Actin

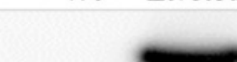

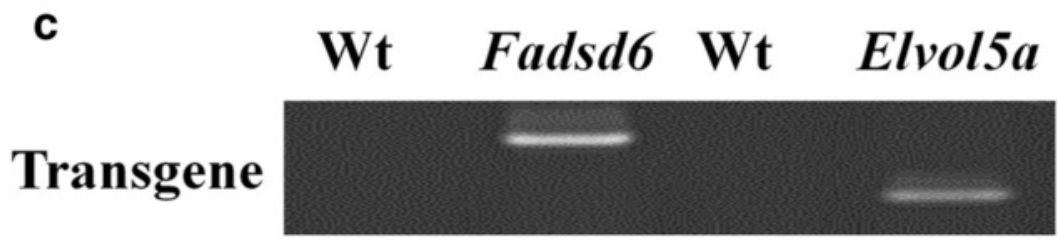

B-Actin

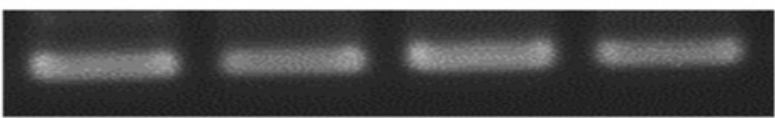

Fig. 1 Transgenic zebrafish specifically express Fadsd6 and Elvol5a in liver. (a) Schematics of the liver-specific activator plasmid pT2-LF-Tta (containing an activator (tTA) driven by the zebrafish fabp10 promoter) and two tetracycline-responsive plasmids (pT2-TRE-fadsd6-TCFP11 and pT2-TRE-elvol5a-TCFP13). All expression cassettes are flanked by the Tol2 transposon. (b) Fluorescence microscopy images of F3 Fadsd6 (red) and Elvol5a (green) transgenic zebrafish larvae, taken at five days (5D) after hatching. (c) RT-PCR was used to detect exogenous gene expression of Fadsd6 and Elvol5a in adult transgenic and Wt zebrafish. (d) Western blots were performed to detect fusion of the V5-tag to Fadsd6 and Elvol5a in transgenic and Wt zebrafish. Mouse $\beta$-actin was used as a positive control 

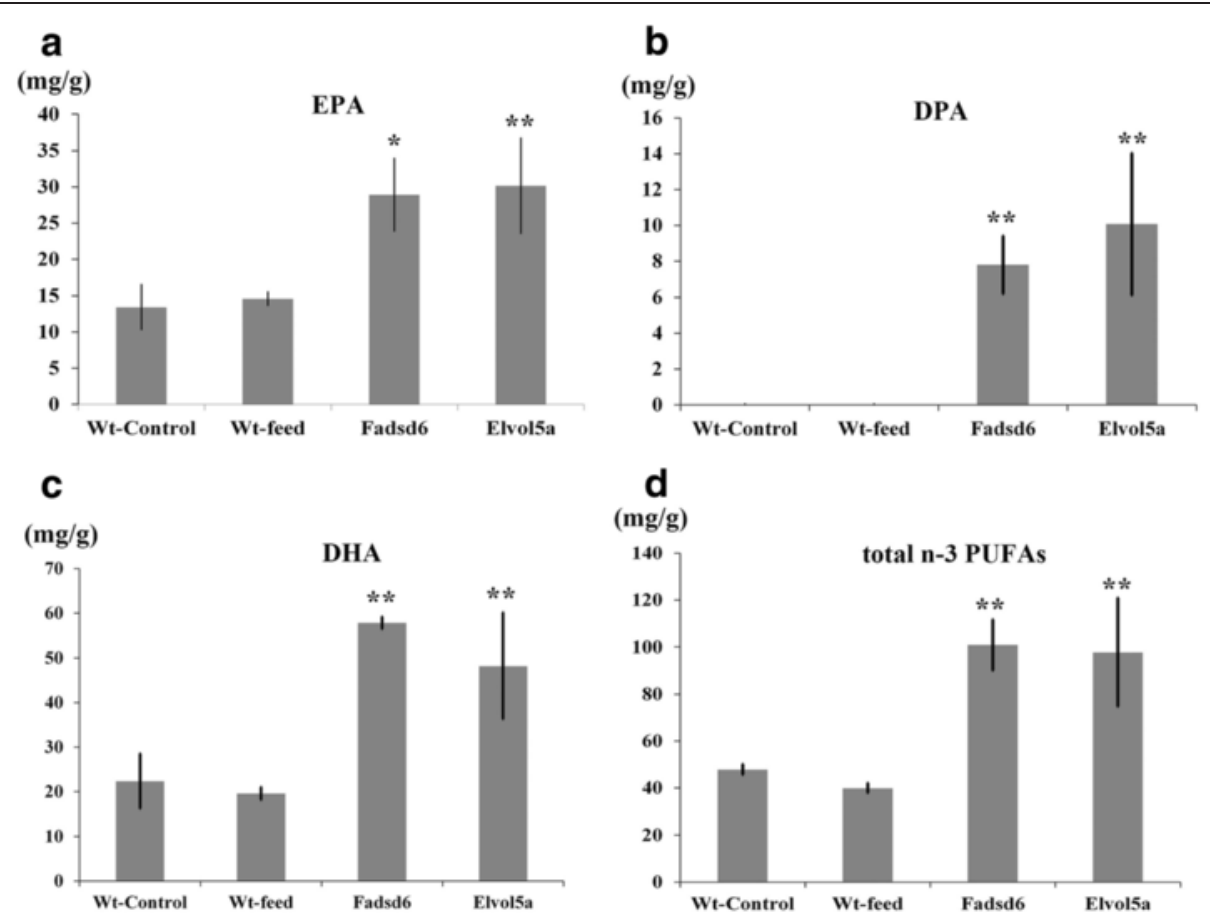

Fig. 2 Polyunsaturated fatty acids in transgenic and Wt zebrafish were measured through gas chromatography-mass spectrometry (GC-MS). (a) Eicosapentaenoic acid (EPA), (b) docosapentaenoic acid (DPA), (c) docosahexenoic acid (DHA), and (d) total n-3 PUFAs were analyzed. Control groups of Wt fish were fed on artemia, while other groups were fed on a commercial diet. The values are milligrams of fatty acid per gram of whole fish body, and are shown as means \pm SEM $(n=5)$. Statistically significant differences between Wt and transgenic fish were determined using T-TEST $\left({ }^{*} p<0.05,{ }^{* *} p<0.01\right)$

Transgenic fish exhibit high survival rates during V. vulnificus challenge

We proceeded to examine whether high n-3 PUFA contents suppress bacterial infection. The bodies of transgenic and Wt fish were IP-injected with $10 \mu \mathrm{L} V$. vulnificus in $\mathrm{BHI}\left(10^{6} \mathrm{CFU} / \mathrm{mL}, \mathrm{NaCl} 1.5 \%\right.$, diluted to $10 \%$ with $1 \mathrm{X}$ PBS). One group of Wt fish was injected with $10 \mu \mathrm{L} 1 \mathrm{X}$ PBS as a negative control. Each group contained at least 30 fish for one test. Fish mortality was determined at $0,1,3,6,9,12,18,24$, and $48 \mathrm{~h}$ after challenge.

Infected fish lost balance in 3-6 h. The ventral side of infected Wt fish was observed to be bleeding at $9 \mathrm{~h}$ and with some speckle of blood on its body after challenge with $V$. vulnificus. However, both two transgenic fish showed slight bleeding. The skin looks quite smooth as normal fish (Fig. 3 (a)). The survival rate of infected Wt fish decreased dramatically between 9-12 h, and dropped to less than $10 \%$ by $24 \mathrm{~h}$ after infection. However, the survival rates of Fadsd6 and Elvol5a transgenic fish remained at up to $70 \%$ at $24 \mathrm{~h}$ after challenge with $V$. vulnificus (Fig. 3 (b)). Taken together, these results indicate that both transgenic lines with higher contents of n-3 PUFAs were more resistant than Wt zebrafish to $V$. vulnificus challenge.

\section{Pathogen-induced liver damage was suppressed in transgenic fish}

Examination of liver histopathological sections revealed that serious liver damage occurred in infected Wt fish. Swollen nuclei, ruptured cells (with an increased ratio of nuclei to cytoplasm), lymphocyte infiltration, and extensive monocyte recruitment were observed within the livers of Wt fish. However, Fadsd6 and Elvol5a transgenic fish did not exhibit substantial damage after infection (Fig. 4 (a)). In addition, TUNEL-assay was performed to identify hepatocyte damage caused by $V$. vulnificus. While cell damage was observed in Wt fish, it was less apparent in transgenic fish (Fig. 4 (b)). The signals of TUNEL assay were quantitated (Additional file 2: Figure S2). In summary, these results indicate that liver damage caused by $V$. vulnificus infection was attenuated in both transgenic lines.

\section{Bacterial growth was inhibited in transgenic fish after V. vulnificus challenge}

We next examined whether bacterial growth after $V$. vulnificus challenge is affected by over-expression of Fadsd6 or Elvol5a. Bacteria were re-cultured on a TCBS agar-plate from tissue homogenates. At $9 \mathrm{~h}$ post-challenge, the bacterial contents of both Wt liver and muscle homogenates 


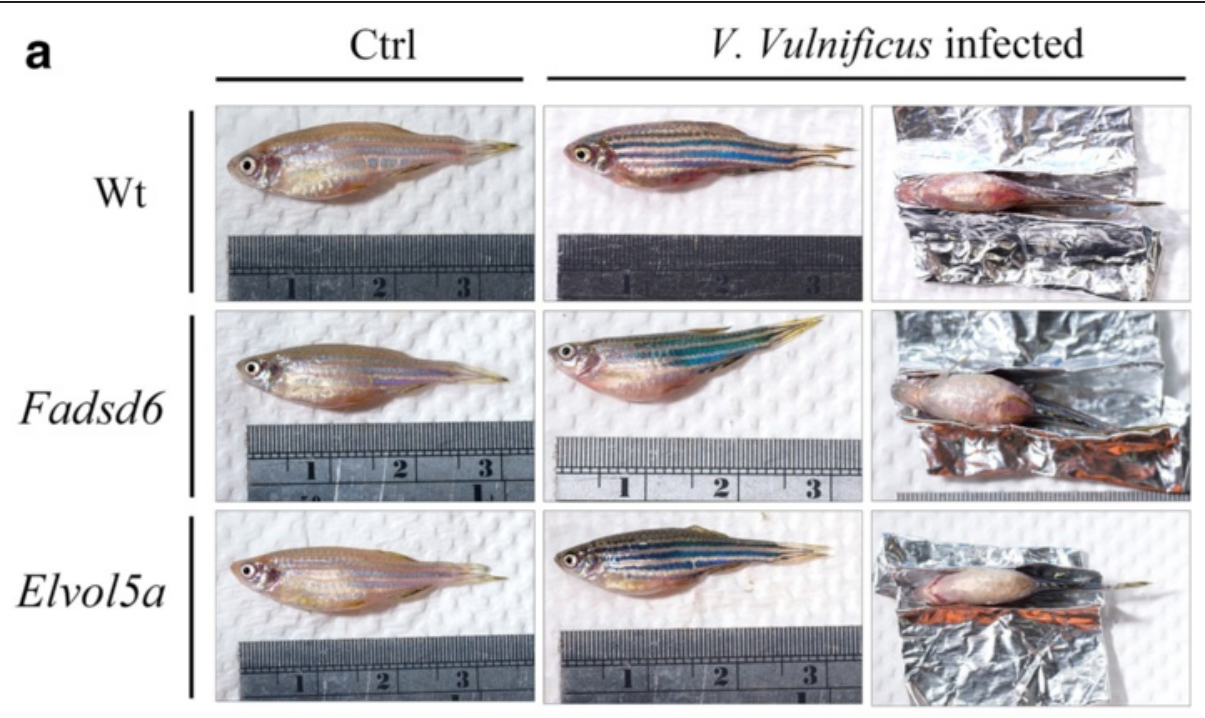

b

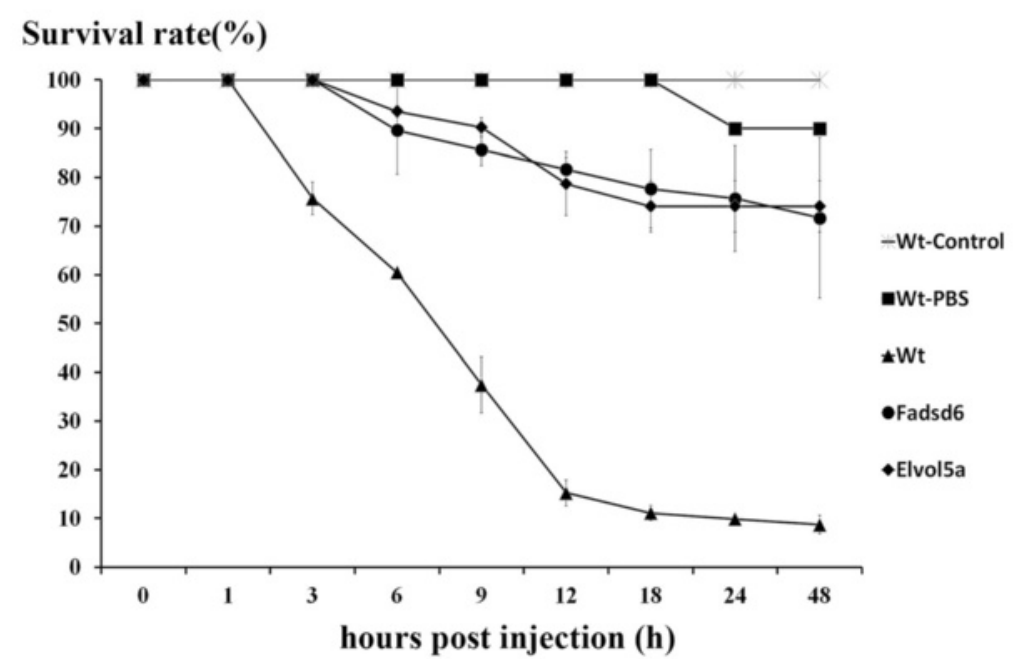

Fig. 3 Survival rates of zebrafish after infection with $V$. vulnificus for $48 \mathrm{~h}$ (a) Photographs of Wt zebrafish control (left) and Wt fish challenged with $V$. vulnificus (middle and right) at $9 \mathrm{~h}$ after IP injection revealed bleeding at the ventral sides of the infected fish body. (b) Survival rates of Wt and transgenic fish injected with $V$. vulnificus (Wt-control was not infected and Wt-PBS was injected with PBS). Survival rates were determined at the indicated times after infection. Each experimental group contained 30 adult zebrafish

were significantly higher than those in non-infected Wt fish. CFU count was 20.64-fold higher in Wt liver than in muscle (Fig. 5 (a)). Moreover, CFU counts were 97.4 and 1353.3-fold higher in Wt liver than in Fadsd6 and Elvol5a transgenic fish, respectively (Fig. 5 (b)). Altogether, these findings indicate that the high contents of $n-3$ PUFAs in both Fadsd6 and Elvol5a transgenic fish can inhibit bacterial growth after $V$. vulnificus challenge.

\section{Inflammatory gene expression was down-regulated in transgenic fish}

Finally, we examined the expression levels of inflammationassociated genes in the livers of Wt and transgenic zebrafish after challenge with $V$. vulnificus. Expression levels of pro-inflammatory genes were strongly increased in Wt fish (Fig. 6). Expression of IL-1 $\beta$ at $9 \mathrm{~h}$ post-injection in Wt fish was 1.8-fold higher than in Fadsd6 transgenic fish, whereas the expression levels at $12 \mathrm{~h}$ were 86.8 -fold and 11.4-fold higher than in Fadsd6 and Elvol5a transgenic fish, respectively (Fig. 6 (a)). For NF-kB, expression in Wt at $9 \mathrm{~h}$ post-injection was 2.3-fold higher than in Fadsd6 transgenic fish, and expression in $\mathrm{Wt}$ at $12 \mathrm{~h}$ postinjection was 2.9-fold and 6.2-fold higher than in Fadsd6 and Elvol5a transgenic fish, respectively (Fig. 6 (b)). Expression of TNF- $\alpha$ at $12 \mathrm{~h}$ post-injection in Wt was 3.0fold and 8.7-fold higher than in Fadsd6 and Elvol5a transgenic fish, respectively (Fig. 6 (c)). For Cox-2a, expression in Wt at $9 \mathrm{~h}$ post-injection was 3.0-fold and 1.8-fold 

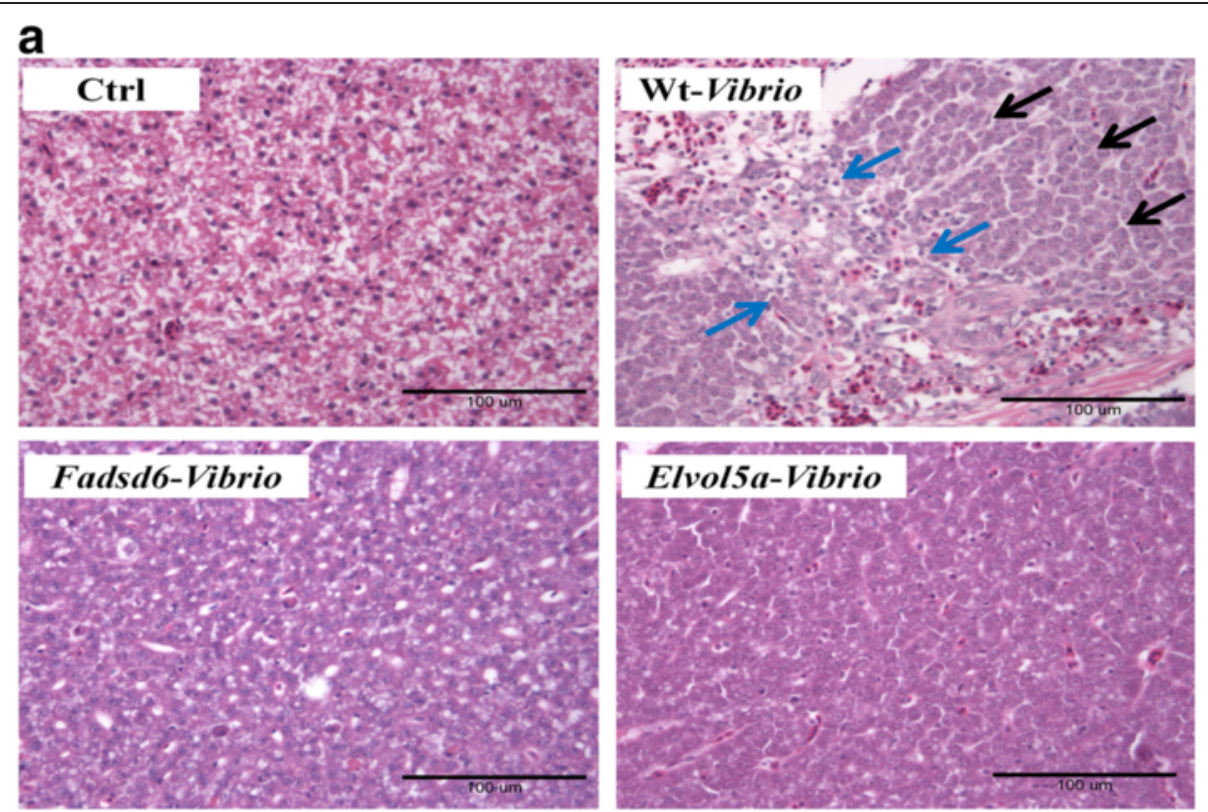

b
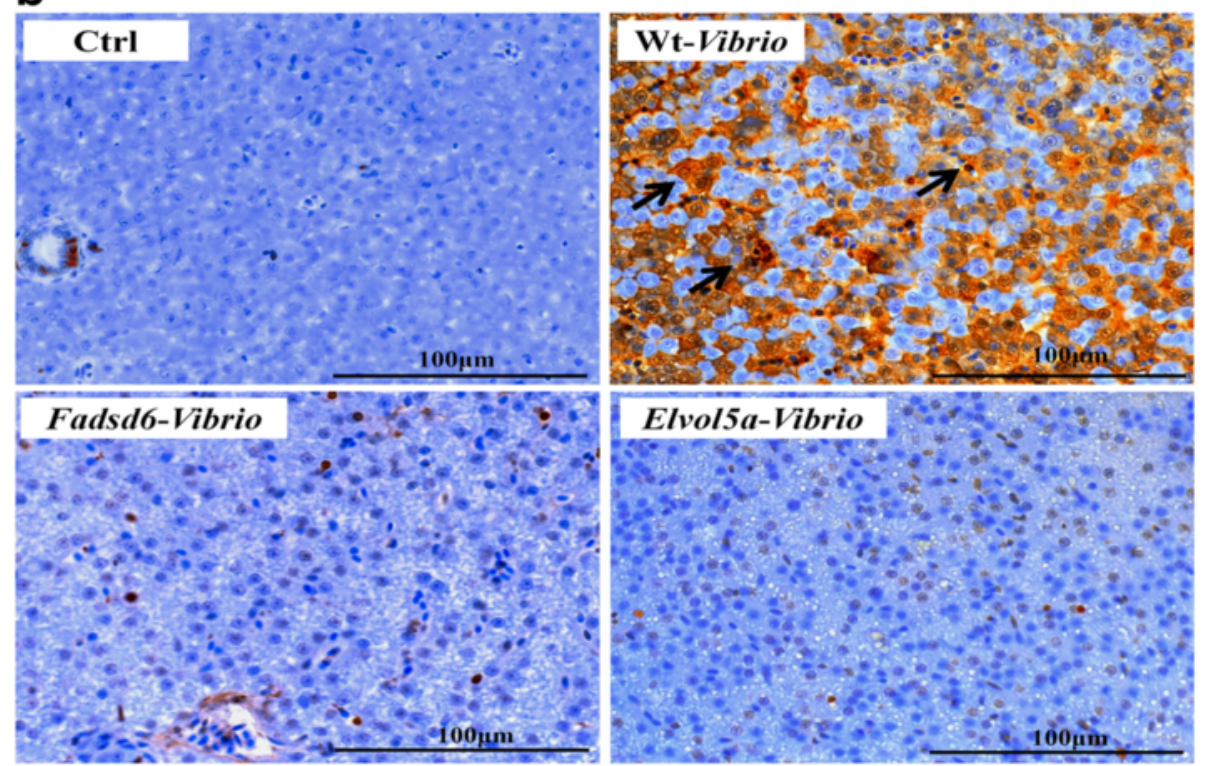

Fig. 4 Histology of liver sections after challenge with V. vulnificus (a) H\&E (Hematoxylin and eosin) staining revealed hepatocyte damage (black arrows) and lymphocyte infiltration (blue arrow) in Wt fish after challenge with V. vulnificus. (b) TUNEL-assay was performed to confirm cell death (brown signals, indicated by black arrows) in Wt fish after challenge with $\mathrm{V}$. vulnificus. Scale bars $=100 \mu \mathrm{m}$

higher than in Fadsd6 and Elvol5a transgenic fish, respectively, while, expression at $12 \mathrm{~h}$ post-injection in Wt was 4.1-fold and 13.7-fold higher than in Fadsd6 and Elvol5a transgenic fish, respectively. (Fig. 6 (d)). For IL-15 and lysozyme, expression levels were suppressed in Wt fish after challenge with $V$. vulnificus. Expression levels of IL15 in Fadsd6 transgenic fish were 5.9-fold and 2.3-fold higher than in Wt at 9 and $12 \mathrm{~h}$ post-injection, respectively, and IL-15 levels in Elvol5a transgenic fish were 3.9fold and 2.6-fold higher than in Wt at 9 and $12 \mathrm{~h}$ postinjection, respectively (Fig. 6 (e)). At 1 and 6 h, expression levels of lysozyme in Fadsd6 transgenic fish were 3.9-fold and 2.2-fold higher than in Wt, respectively (Fig. 6 (f)).

Overall, these results indicate that the expression levels of pro-inflammatory genes are decreased in both Fadsd6 and Elvol5a transgenic fish, and this may suppress the inflammatory response to challenge with $V$. vulnificus within a $24 \mathrm{~h}$ window.

\section{Discussion}

Long-chain n-3 PUFAs, such as EPA and DHA, are wellknown to have many beneficial effects on biological 


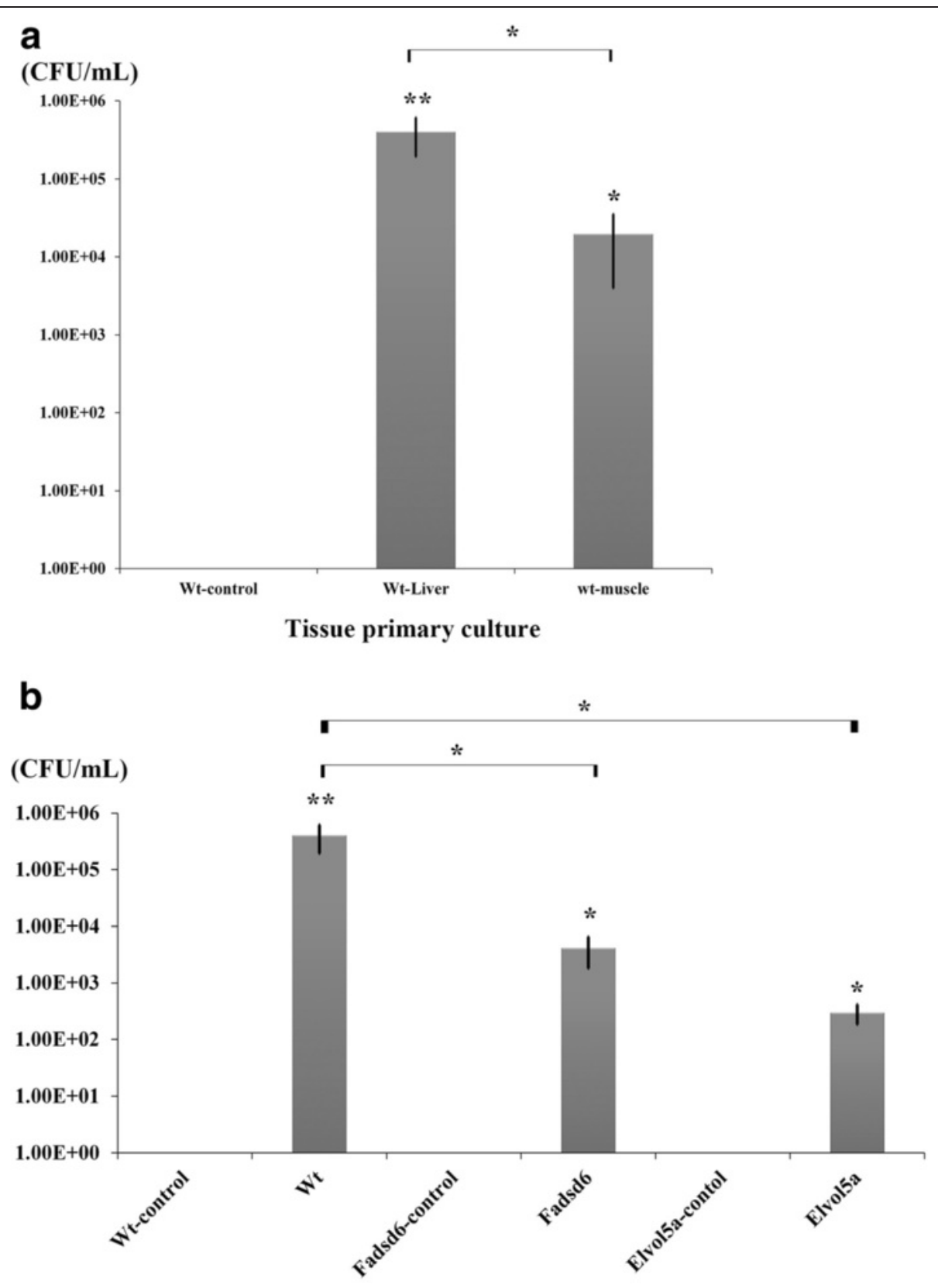

Tissue primary culture

Fig. 5 Bacterial contents were determined in zebrafish after challenge with $V$. vulnificus. Tissues were collected and cultured on TCBS agar plates. (a) Bacterial amounts (CFU/mL) were determined in Wt liver or muscle and $(\mathbf{b})$ in liver of Fadsd6 or Elvol5a transgenic fish. Values are presented as means \pm SEM. Significance was determined by T-TEST $\left({ }^{*} P<0.05,{ }^{*} P<0.01\right)$

functions. However, total fat content and the ratio of $n-3$ to n-6 PUFAs in food have decreased significantly since the Industrial Revolution [30]. Moreover, the efficiencies of desaturases and elongase in mammals are too low to generate high n-3 PUFA contents. Therefore, in 2005, 2007, and 2008, Alimuddin et al. established transgenic zebrafish that expressed Fadsd5/6 and Elvol5a under the control of the $\beta$-actin promoter $[3,24,31]$. Transgenic zebrafish described in these earlier studies synthesized about 1.3-fold more EPA, DPA, and DHA than Wt. In our findings, the expression levels of both the endogenous desaturase (Fadsd2) and elongase (Elovl2) genes were significantly higher in Wt liver than in muscle (Additional file 3: Figure S1). Taken together, the evidences show these desaturase and elongase genes are tissue specific which enhances the efficiency of long chain fatty acid 


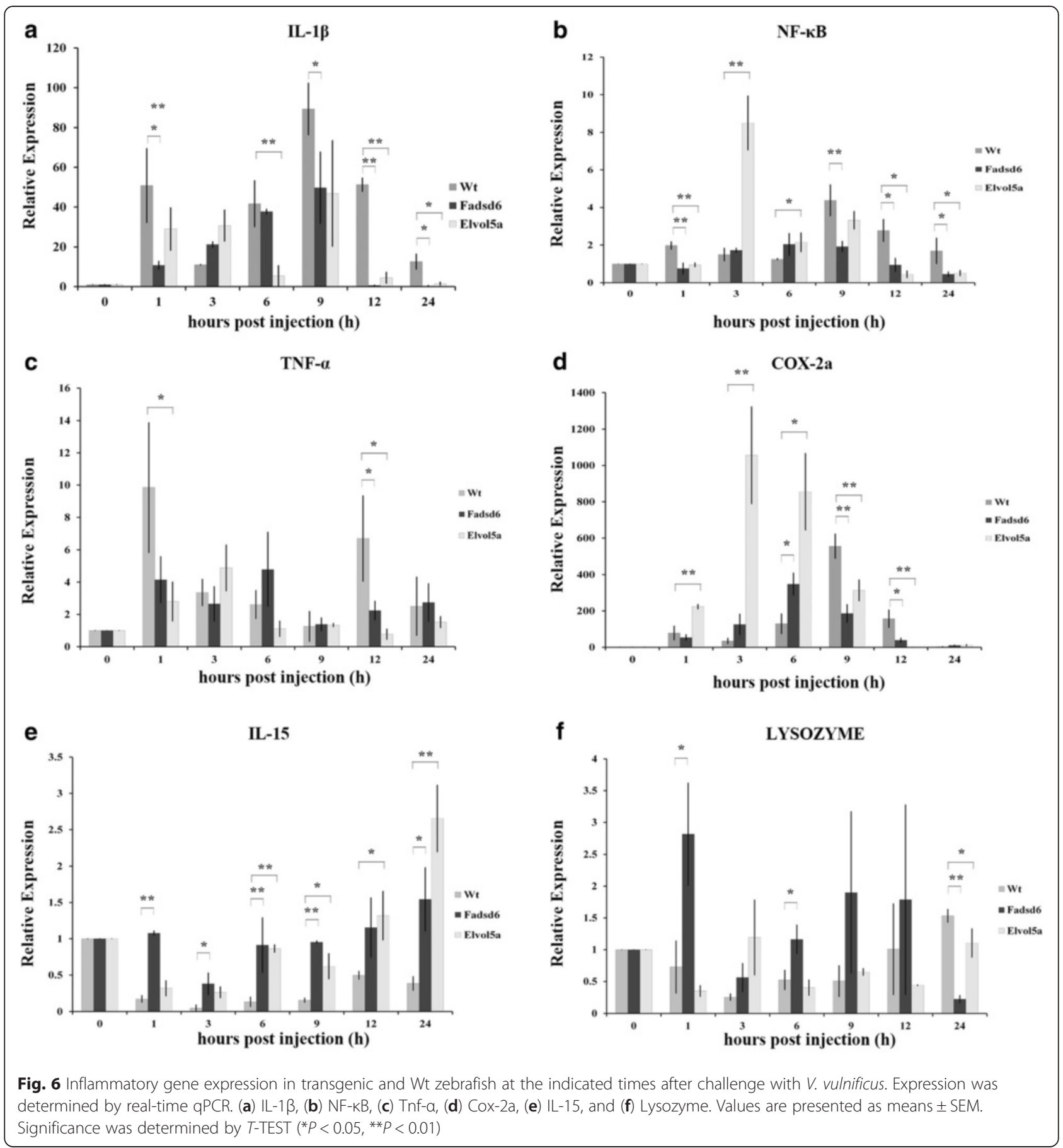

synthesis. A more recent study described the establishment of transgenic zebrafish specifically expressing Fadsd5 and Fadsd6 in the muscle, through the use of the myosin light chain (mlc3) promoter [32]. EPA content in Fadsd5 and Fadsd6 transgenic fish were 2.0 and 1.9-fold higher than in Wt, respectively, but there was no significant difference in DHA and DPA contents. Indeed, this aforementioned study demonstrated that tissue-specific expression of desaturases and elongase is sufficient to enhance n-3 PUFA biosynthesis in transgenic fish. Transgenic fish expressing Fadsd6 and Elvol5a specifically in the liver under the control of the Fabp10 promoter was created for the following reasons: (1) the liver is the major organ for lipid metabolism; (2) Fadsd6 has been shown to be rate limiting for the conversion of ALA to EPA in the lipid biosynthesis pathway; and (3) Elvol5a improves the production of DHA and DPA in the n-3 PUFA biosynthesis pathway [33, 34]. When body weights are similar, Fadsd6 and Elvol5a transgenic 
fish synthesized 2.5-fold more n-3 PUFAs than Wt. The contents of n-3 PUFAs were also higher than those in transgenic fish expressing the same genes under the control of $\beta$-actin or mlc3 promoter. Liver specific-expression of these genes is thus more efficient than global expression at producing $\mathrm{n}-3$ PUFAs.

A separate study showed that increasing n-3 PUFA content reduced the generation of eicosanoids from AA and promoted the generation of $\mathrm{PGH}_{3}$ [35]. These $\mathrm{n}-3$ PUFAs compete with the enzymes that convert AA into PG, thereby decreasing the production of pro-inflammatory prostaglandins. Furthermore, in vitro studies have indicated that EPA suppresses the growth of Staphylococcus aureus and Propionibacterium acnes $[15,36]$. It has also been shown that transgenic expression of salmon delta- 5 and delta-6 desaturase in zebrafish muscle inhibits Vibrio alginolyticus growth [32].

V. vulnificus causes serious, fulminant sepsis, mostly in patients with chronic liver diseases. After reaching the blood stream, the bacteria begin to proliferate and produce two main cytotoxins, VvhA and MARTXv $v_{\mathrm{v}}$. VvhA, a haemolysin, is cytotoxic to host cells by causing necrosis or apoptosis depending on the amount of bacteria which cells exposure. MARTXv $v_{\mathrm{v}}$ is required for $V$. vulnificus survival during infection by protecting itself from swallowing by phagocytes. Both cytotoxins build a microenvironment for $V$. vulnificus to facilitate bacterial dissemination and contribute to tissue damage [37]. To elucidate the anti-bacterial effect of n-3 PUFAs, we analyzed the immune and anti-inflammatory response of transgenic zebrafish in this study. We observed that transgenic fish were more resistant to the damaging effects of $V$. vulnificus infection, with repressed growth of $V$. vulnificus in the liver resulting in decreased mortality and reduced hepatocyte damage. Further, the bacterial contents in Wt liver were higher than in muscle (Fig. 5 (a)). It seems that the pathogen attacked the liver through the hepatic portal vein within a few hours after IP-injection. VvhA from $V$. vulnificus caused haemolysis and iron availability has been found to be related in pathogenic vibrios with haemolysin production [38]. In addition, liver is the storage depot of iron which is important to supply iron for accelerated erythropoiesis following a substantial loss of blood [39]. In clinical cases, patients with liver disease are more likely than healthy patients to die after $V$. vulnificus infection [40]. Therefore, we focused on liver and determined the expressions of inflammatory related genes.

NF- $\mathrm{kB}$ is activated by $V$. vulnificus infection [41]. The pro-inflammatory genes TNF- $\alpha$ and IL- $1 \beta$ are induced by the activation of NF- $\mathrm{KB}$ following LPS-induced infection [42]. However, n-3 PUFAs can directly bind PPAR- $\alpha$ to prevent the phosphorylation and translocation of NF- $\mathrm{B}$ [43]. In agreement with this earlier finding, we describe here that NF- $\mathrm{kB}$ expression is suppressed in
Fadsd6 and Elvol5a transgenic fish after $V$. vulnificus infection (Fig. 6). In addition, high n-3 PUFAs contents in transgenic fish reduced the expression of TNF- $\alpha$ and IL- $1 \beta$ to mitigate the spread of inflammation. Cox-2a, an inflammatory marker, is also expressed during many inflammatory responses induced by different pathogens [44]. In our results, the highest expression peaks of Cox-2a were at 3 and $6 \mathrm{~h}$ in Elvol5a and Fadsd6 transgenic fish, respectively; the expression peaks for transgenic fish occurred earlier than in Wt fish $(9 \mathrm{~h})$. As such, during the inflammatory process, the expression of Cox-2a in transgenic fish is rapidly increased to convert EPA to $\mathrm{PGH}_{3}$. Anti-inflammatory cytokines may be elevated to diminish the inflammatory response after $V$. vulnificus infection.

Moreover, IL-15 and lysozyme are secreted by macrophages and recruited to sites of infection to clear pathogens [45]. The expression levels of IL-15 and lysozyme were reduced in Wt fish after challenge with $V$. vulnificus as compared to transgenic fish. Expression of these factors can facilitate the removal of pathogen and increase the survival rate after infection. In addition, previous study demonstrated the potency of anti-bacteria of DHA is the highest than other long chain PUFAs [15]. With high contents of DHA in Fadsd6 transgenic fish (Fig. 2c); the expression levels of IL-15 and lysozyme were higher in Fadsd6 fish than Elvol5a fish. Our results may indicate high contents of DHA can enhance the expression level of IL-15 and lysozyme (Fig. 6e/f).

In summary, the transgenic fish described here can be used as an in vivo model for studying the bio-function of n-3 PUFAs, and for increasing EPA and DHA production in aquaculture fish to confer anti-bacterial and/or cold resistance. High n-3 PUFA content zebrafish may also provide a convenient platform with which to study the molecular mechanisms behind potentially lethal inflammation and septicemia due to $V$. vulnificus infection in human.

\section{Conclusion}

In this study, liver-specific expression of salmon Fadsd6 or Elvol5a in transgenic fish was shown to enhance the bio-synthesis of n-3 PUFAs. Furthermore, transgenic fish exhibited resistance to $V$. vulnificus infection, with enhanced survival and anti-inflammatory effects. Moreover, these transgenic lines may serve as an in vivo model for studying the effects of n-3 PUFAs on bacterial infection and inflammation-associated diseases.

\section{Additional files}

Additional file 1: Table S1. The quantitatiion of eicosapentaenoic acid (EPA), docosahexaenoic acid (DHA), docosapentaenoic acid (DPA) and total n-3 PUFA content in transgenic and Wt zebrafish. (DOCX 18 kb) 
Additional file 2: Figure S2. Quantitation of TUNEL signal analysis. The supplementary result is related to Fig. $4 \mathrm{~b}$. The TUNEL signals were counting. Values are presented as means \pm SEM. Significance was determined by T-TEST (***P<0.001). (JPEG $259 \mathrm{~kb}$ )

Additional file 3: Figure S1. Endogenous gene expressions of fatty acid synthesis genes were determined by real-time qPCR. The endogenous fatty acid synthesis genes, Fadsd2 (Fatty acid desaturase delta 2), Elovl2 (Elongase 2) and Elovl5 (Elongase 5) of zebrafish liver and muscle were analysis. (JPEG $301 \mathrm{~kb}$ )

\section{Abbreviations}

n-3 PUFAs: Omega-3 polyunsaturated fatty acids; AA: Arachidonic acid (n-6, 20:4); ALA: a-linolenic acid (n-3, 18:3); DPA: Docosapentaenoic acid $(n-3,22: 5)$; DHA: Docosahexanoic acid (n-3, 22:6); EPA: Eicosapentaenoic acid (n-3, 20:5); Fadsd: Fatty acid desaturase; $\mathrm{BF}_{3}$ : Boron trifluoride; TCBS: Thiosulfate-citratebile salts-sucrose; LPS: Popolysaccharide; V. vulnificus: Vibrio vulnificus; Cox-2a: Cyclooxygenase-2a; IL-1 $\beta$ : Interleukin-1 beta; NF-kB: Nuclear factor kappaB; TNF-a: Tumor necrosis factor-alpha; UPL: Universal probe library.

\section{Competing interests}

The authors declare that they have no competing interest.

\section{Authors' contributions}

$\mathrm{CLC}$ and SJH designed the experiments. CLC performed the experiments and analyzed the data. CLC, SJH, CLW, HYG and JLW participated in drafting and revision of the manuscript. All authors read and approved the final manuscript.

\section{Acknowledgements}

This study was supported by a grant from the Innovative Translational Agricultural Research Grant (ITAR) (2015AS002), and by internal funding from the Institute of Cellular and Organismic Biology, Academia Sinica, Taiwan. We thank the Taiwan Mouse Clinic (MOST 103-2325-B-001-015) which is funded by the National Research Program for Biopharmaceuticals (NRPB) at the Ministry of Science and Technology (MOST) of Taiwan for technical support in histopathological staining experiment. We thank Dr. Hong-Nong Chou who supplied the instrument of GC-MS (Agilent 5970C) and Dr. Wen-Liang Liao who assisted for fatty acid extraction experiments.

\section{Author details \\ ${ }^{1}$ Institute of Cellular and Organismic Biology, Academia Sinica, Taipei 115, Taiwan. ${ }^{2}$ Institute of Bioscience and Biotechnology, National Taiwan Ocean University, Keelung 202, Taiwan. ${ }^{3}$ Institute of Fisheries Science, National Taiwan University, Taipei 106, Taiwan. ${ }^{4}$ Department of Aquaculture, National Taiwan Ocean University, Keelung 202, Taiwan. ${ }^{5}$ Institute of Biotechnology, National Changhua University of Education, Changhua 500, Taiwan. ${ }^{6}$ Department of Biological Science and Technology, National Pingtung University of Science and Technology, Pingtung 912, Taiwan.}

Received: 1 June 2015 Accepted: 16 October 2015 Published online: 17 November 2015

\section{References}

1. Merino DM, Ma DW, Mutch DM. Genetic variation in lipid desaturases and its impact on the development of human disease. Lipids Health Dis. 2010;9:63.

2. Burdge GC, Calder PC. Conversion of alpha-linolenic acid to longer-chain polyunsaturated fatty acids in human adults. Reprod Nutr Dev. 2005:45(5):581-97.

3. Alimuddin, Yoshizaki G, Kiron V, Satoh S, Takeuchi T. Enhancement of EPA and DHA biosynthesis by over-expression of masu salmon $\Delta 6$-desaturaselike gene in zebrafish. Transgenic Res. 2005;14(2):159-65.

4. Li Y, Monroig O, Zhang L, Wang S, Zheng X, Dick J.R, et al. Vertebrate fatty acyl desaturase with Delta4 activity. Proc Natl Acad Sci USA. 2010;107(39):16840-5.

5. Hibbeln JR, Nieminen LR, Blasbalg TL, Riggs JA, Lands WE. Healthy intakes of n-3 and n-6 fatty acids: estimations considering worldwide diversity. Am J Clin Nutr. 2006;83(6 Suppl):1483S-93S.
6. Wong CK, Wong PP, Chu LM. Heavy metal concentrations in marine fishes collected from fish culture sites in Hong Kong. Arch Environ Contam Toxicol. 2001;40(1):60-9.

7. Yokoo EM, Valente JG, Grattan L, Schmidt SL, Platt L, Silbergeld EK, et al. Low level methylmercury exposure affects neuropsychological function in adults. Environ Health. 2003;2(1):8

8. Cleland LG, James MJ, Proudman SM. Fish oil: what the prescriber needs to know. Arthritis Res Ther. 2006:8(1):202

9. Kromhout D, Yasuda S, Geleijnse JM, Shimokawa H. Fish oil and omega-3 fatty acids in cardiovascular disease: do they really work? Eur Heart J. 2012;33(4):436-43.

10. Moreno C, Macías A, Prieto A, de la Cruz A, González T, Valenzuela C. Effects of n-3 Polyunsaturated Fatty Acids on Cardiac Ion Channels. Front Physiol. 2012;3:245.

11. Lefebvre P, Chinetti G, Fruchart JC, Staels B. Sorting out the roles of PPAR alpha in energy metabolism and vascular horneostasis. J Clin Investig. 2006;116(3):571-80.

12. Kota BP, Huang TH, Roufogalis BD. An overview on biological mechanisms of PPARs. Pharmacol Res. 2005;51(2):85-94.

13. Jump DB. N-3 polyunsaturated fatty acid regulation of hepatic gene transcription. Curr Opin Lipidol. 2008;19(3):242-7.

14. Hanada T, Yoshimura A. Regulation of cytokine signaling and inflammation. Cytokine Growth Factor Rev. 2002;13:8.

15. Desbois AP, Lawlor KC. Antibacterial activity of long-chain polyunsaturated fatty acids against Propionibacterium acnes and Staphylococcus aureus. Mar Drugs. 2013;11(11):4544-57.

16. $\mathrm{LI} H$, Ruan XZ. EPA and DHA reduced LPS-induced inflammation response in HK-2 cells: evidence for a PPAR-r-dependent mechanism. Kidney Int 2005;67:8.

17. Hlady WG, Klontz KC. The epidemiology of Vibrio infections in Florida, 1981-1993. J Infect Dis. 1996;173(5):1176-83.

18. Kim DM, Lym Y, Jang SJ, Han H, Kim YG, Chung CH, Hong SP. In vitro efficacy of the combination of ciprofloxacin and cefotaxime against Vibrio vulnificus. Antimicrob Agents Chemother. 2005;49(8):3489-91.

19. Horseman MA, Surani S. A comprehensive review of Vibrio vulnificus: an important cause of severe sepsis and skin and soft-tissue infection. Int J Infect Dis. 2011;15(3):e157-66.

20. Tison DL, Nishibuchi M, Greenwood JD, Seidler RJ. Vibrio-vulnificus biogroup-2 - new biogroup pathogenic for eels. Appl Environ Microbiol. 1982;44(3):640-6.

21. Schmid JA, Birbach A. IkappaB kinase beta (IKKbeta/IKK2/IKBKB)-a key molecule in signaling to the transcription factor NF-kappaB. Cytokine Growth Factor Rev. 2008;19(2):157-65.

22. Zhang WW, Sun K, Cheng S, Sun L. Characterization of DegQVh, a serine protease and a protective immunogen from a pathogenic Vibrio harveyi strain. Appl Environ Microbiol. 2008;74(20):6254-62.

23. Hor L, Chang TT, Wang ST. Survival of Vibrio vulnificus in Whole Blood from Patients with Chronic Liver Diseases: Association with Phagocytosis by Neutrophils and Serum Ferritin Levels. J Infect Dis. 1999;179(1):275-8.

24. Alimuddin, Kiron V, Satoh S, Takeuchi T, Yoshizaki G. Cloning and overexpression of a masu salmon (Oncorhynchus masou) fatty acid elongaselike gene in zebrafish. Aquaculture. 2008;282(1-4):13-8.

25. "A Guide for the Laboratory Use of Zebrafish (Danio rerio)", 5th edition edited by Westerfield, M. in 2007

26. Liu W, Chen JR, Hsu CH, Li YH, Chen YM, Lin CY, et al. A Zebrafish Model of Intrahepatic Cholangiocarcinoma by Dual Expression of Hepatitis B Virus X and Hepatitis C Virus Core Protein in Liver. Hepatology. 2012;56(6):2268-76.

27. Peng KC, Pan CY, Chou HN, Chen JY. Using an improved Tol2 transposon system to produce transgenic zebrafish with epinecidin-1 which enhanced resistance to bacterial infection. Fish Shellfish Immunol. 2010;28(5-6):905-17.

28. Folch J, Lees M, Sloane Stanley GH. A simple method for the isolation of total lipides from animal tissues. J Biol Chem. 1957;226:497-509.

29. Abu EO, Oluwatowoju I. Omega-3 index determined by gas chromatography with electron impact mass spectrometry. Prostaglandins Leukot Essent Fatty Acids. 2009:80(4):189-94.

30. Berquin IM, Edwards IJ, Chen YQ. Multi-targeted therapy of cancer by omega-3 fatty acids. Cancer Lett. 2008;269(2):363-77.

31. Alimuddin, Yoshizaki G, Kiron V, Satoh S, Takeuchi T. Expression of masu salmon delta5-desaturaselike gene elevated EPA and DHA biosynthesis in zebrafish. Mar Biotechnol (NY). 2007;9(1):92-100. 
32. Wang YD, Peng KC, Wu JL, Chen JY. Transgenic expression of salmon delta5 and delta-6 desaturase in zebrafish muscle inhibits the growth of Vibrio alginolyticus and affects fish immunomodulatory activity. Fish Shellfish Immunol. 2014:39(2):223-30.

33. Nguyen P, Leray V, Diez M, Serisier S, Le Bloc'h J, Siliart B, Dumon H. Liver lipid metabolism. J Anim Physiol Anim Nutr (Berl). 2008;92(3):272-83.

34. Baylin A, Ruiz-Narvaez E. a-Linolenic acid, d6-desaturase gene polymorphism, and the risk of nonfatal myocardial infarction. Am J Clin Nutr. 2007:85:6.

35. Wu D, Meydani SN. n-3 Polyunsaturated fatty acids and immune function. Proc Nutr Soc. 1998;57:6.

36. Desbois AP, Mearns-Spragg A, Smith VJ. A fatty acid from the diatom Phaeodactylum tricornutum is antibacterial against diverse bacteria including multi-resistant Staphylococcus aureus (MRSA). Mar Biotechnol (NY). 2009;11(1):45-52.

37. Hor L-I, Chen C-L. Cytotoxins of Vibrio vulnificus: Functions and roles in pathogenesis. Bio Medicine. 2013;3(1):19-26.

38. Lee HJ, Kim JA, Lee MA, Park SJ, Lee KH. Regulation of haemolysin (VvhA) production by ferric uptake regulator (Fur) in Vibrio vulnificus: repression of vvhA transcription by Fur and proteolysis of VvhA by Fur-repressive exoproteases. Mol Microbiol. 2013;88(4):813-26.

39. Emerit J, Beaumont C, Trivin F. Iron metabolism, free radicals, and oxidative injury. Biomed Pharmacother. 2001;55(6):333-9.

40. Chen Y, Satoh T, Tokunaga O. Vibrio vulnificus infection in patients with liver disease: report of five autopsy cases. Virchows Arch. 2002;441(1):88-92.

41. Lee SJ, Jung YH, Oh SY, Song EJ, Choi SH, Han HJ. Vibrio vulnificus VvhA induces NF-kappaBdependent mitochondrial cell death via lipid raftmediated ROS production in intestinal epithelial cells. Cell Death Dis. 2015;6:1655

42. Secombes CJ, Wang T, Hong S, Peddie S, Crampe M, Laing KJ, Cunningham C, Zou J. Cytokines and innate immunity of fish. Dev Comp Immunol. 2001;25(8-9):713-23.

43. Li H, Ruan XZ, Powis SH, Fernando R, Mon WY, Wheeler DC, Moorhead JF, Varghese $Z$. EPA and DHA reduce LPS-induced inflammation responses in HK-2 cells: evidence for a PPAR-gamma-dependent mechanism. Kidney Int. 2005;67(3):867-74.

44. Li X, Yu Y, Funk CD. Cyclooxygenase-2 induction in macrophages is modulated by docosahexaenoic acid via interactions with free fatty acid receptor 4 (FFA4). Faseb Journal. 2013;27(12):4987-97.

45. Secombes CJ, Wang T, Bird S. The interleukins of fish. Dev Comp Immunol. 2011:35(12):1336-45

\section{Submit your next manuscript to BioMed Central and take full advantage of:}

- Convenient online submission

- Thorough peer review

- No space constraints or color figure charges

- Immediate publication on acceptance

- Inclusion in PubMed, CAS, Scopus and Google Scholar

- Research which is freely available for redistribution 